\title{
Serum levels of androgens in acne \& their role in acne severity
}

\author{
Usma Iftikhar ${ }^{1}$, Nakhshab Choudhry²
}

\begin{abstract}
Objectives: To correlate acne severity with elevated androgen levels and to compare androgen levels between cases and controls.

Methods: This case-control study was carried out in the Department of Dermatology, Mayo Hospital, Lahore from March 2016 - March 2017. Two hundred and seventy patients and eighty age and gendermatched controls were recruited after ethical approval and informed consent and categorized into mild, moderate and severe acne. Severity was correlated with serum Testosterone, Dihydrotestoststerone and Dihydroepiandrosterone Sulphate levels. Quantitative variables were expressed as median and percentiles, comparisons done by Mann-Whitney and correlations by Spearman correlation. P-value of $<0.05$ was considered statistically significant.

Results: There were 142 (41\%) males and 208 (59\%) females. Ninety-Seven patients had mild, 108 moderate and 65 had severe disease. Median hormonal levels were $3.5 \mathrm{ng} / \mathrm{ml}, 184 \mathrm{pg} / \mathrm{ml}$ and $0.82 \mathrm{ug} / \mathrm{dl}$ for Testosterone, Dihydrotestosterone and Dihydroepiandrosterone Sulphate respectively which differed significantly between cases and controls. There was no correlation with severity but the levels differed significantly between the different grades in case of Testosterone and DHEAS.

Conclusion: Androgens are not directly correlated with acne severity, but affect acne severity as seen in difference between their levels in different grades of acne. Anti-androgens may be initiated early in acne resistant to conventional therapy.
\end{abstract}

KEYWORDS: Acne vulgaris, Androgens, Hyperandrogenism, Acne Severity.

How to cite this:

doi: https://doi.org/10.12669/pjms.35.1.131

Iftikhar U, Choudhry N. Serum levels of androgens in acne \& their role in acne severity. Pak J Med Sci. 2019;35(1):146-150. doi: https://doi.org/10.12669/pjms.35.1.131

This is an Open Access article distributed under the terms of the Creative Commons Attribution License (http://creativecommons.org/licenses/by/3.0), which permits unrestricted use, distribution, and reproduction in any medium, provided the original work is properly cited.

1. Dr. Usma Iftikhar, FCPS.

Department of Dermatology,

Mayo Hospital,

2. Dr. Nakhshab Choudhry, PhD. Professor \& Chairman, Department of Biochemistry,

1, 2: King Edward Medical University, Lahore, Pakistan.

Correspondence:

Dr. Usma Iftikhar, FCPS.

Senior Registrar, Dermatology,

357 AA, Phase-IV, DHA,

Lahore, Pakistan.

Email: usmaiftikhar@gmail.com

* Received for Publication:

* $1^{\text {st }}$ Revision Received:

* $2^{\text {nd }}$ Revision Received:

* Final Revision Accepted:
August 30, 2018

September 3, 2018

December 3, 2018

December 13, 2018

\section{INTRODUCTION}

Acne is one of the commonest dermatological disorders with a prevalence of $22 \%{ }^{1}$ It is a disease of the pilosebaceous follicle with presence in $70-95 \%$ of dermatological patients. ${ }^{2}$ Endocrine mechanisms control the components of sebocyte function - namely lipid synthesis, proliferation and differentiation. ${ }^{3}$ Androgens upregulate sebaceous gland function by binding to the nuclear androgen receptors (ARs). Highest density of these has been demonstrated in sebaceous glands.

Testosterone (T) and dihydrotestosterone (DHT) are synthesized in the skin and bind to the androgen receptor. ${ }^{4}$ Clinical studies support the role of androgenic hormones in acne pathogenesis and 
cite the approximation of acne onset with surge of dihydroepiandrosterone sulphate (DHEA-S), acne in congenital adrenal hyperplasia (CAH), sudden onset acne, androgens administration leading to acne and improvement by androgen receptor blockers.

DHEA-S was found to be in the highest concentration in both sexes, which is converted by sebocytes and dermal papilla into testosterone and DHT. Androgen receptor (AR) malfunction is associated with acne. ${ }^{5}$ Patients with androgen excess, like Cushing's syndrome, Polycystic Ovaries (PCOs) and $\mathrm{CAH}$, can all have acne. However, there are conflicting studies regarding androgen levels in acne severity. A positive relationship was not found between grades of acne severity and hyperandrogenism. ${ }^{6}$ In some, raised DHEA-S levels were found. ${ }^{7}$ Androgens exhibit increased receptor sensitivity and 5a-reductase activity leading to high DHT levels. ${ }^{8}$

Acne may be associated with endocrinopathies, PCOs and ovarian tumours, if associated with hyperandrogenism. It is important to standardize the hormonal profile and control relapses in breakouts of acne. Treatment includes androgen receptor blocker, lowering androgen production by adrenals and ovaries. ${ }^{9}$

The objectives of this study were to correlate acne severity with elevated androgen levels and to compare androgen levels between cases and controls.

\section{METHODS}

Two hundred and seventy acne patients and eighty age and gender matched controls presenting to the outpatient department of Mayo Hospital, Lahore were included. Patients were studied for hyperandrogenism. Patients having features of hyperandrogenism clinically (e.g. hirsutism) were excluded as well as those patients having a known cause of hyperandrogenism like PCOS or oral contraceptives in case of females or Cushing's syndrome (as tested on Ultrasonography and fasting serum cortisol levels). Patients presenting for the first time were selected. After approval from the ethical committee and informed consent, after ruling out polycystic ovaries on ultrasound and after basal serum cortisol, fasting androgen levels were recorded. Levels were measured by ELISA using kits by Diasource Belgium and tests performed on Diamate 310. Levels of androgens were compared between cases and controls and correlated with acne severity. All data was entered into SPSS 20. Since the distribution was nonnormal, quantitative data was expressed in median and percentiles. Non-parametric tests like MannWhitney were done for comparison between two groups. Correlation was measured by Spearman Correlation. A P value of $<0.05$ was considered statistically significant.

\section{RESULTS}

There were 142 (40.5\%) males and 208 (59.4\%) females. In cases, there were 155 (57\%) females and $115(43 \%)$ males, whereas in controls, there were 54 $(67 \%)$ females and $26(33 \%)$ males. In both males and females, the median age was 20 years. Median age of cases was 20 years and median age of controls was 21 years. Ninety-Seven $(36 \%)$ of patients had mild disease, $108(40 \%)$ had moderate disease and $65(24 \%)$ had severe disease.

In the comparison of hormonal levels between cases and controls, there was a statistically significant difference (Table-I) tested by MannWhitney Test.

In the correlation of serum levels of hormones with severity, there was no significant correlation (Table-II).

In the comparison of hormonal levels between different grades of severity, there was a significant difference in case of Testosterone and DHEAS

Table-I: Comparison of Androgenic Hormones between Cases and Controls.

\begin{tabular}{llcccc}
\hline Hormones & & $N$ & Median & $I R$ & $P$ \\
\hline Testosterone $(\mathrm{ng} / \mathrm{ml})$ & Case & 270 & 0.82 & $(0.56,5.77)$ & $<0.001$ \\
& Control & 80 & 0.45 & $(0.36,4.99)$ & \\
DHT $(\mathrm{pg} / \mathrm{ml})$ & Case & 270 & 350.24 & $(280,545.7)$ & $<0.001$ \\
& Control & 80 & 280 & $(215,375.45)$ & \\
DHEAS $(\mu \mathrm{g} / \mathrm{dl})$ & Case & 270 & 1.84 & $(1.27,2.55)$ & $<0.001$ \\
& Control & 80 & 0.72 & $(0.52,2.42)$ & \\
\hline
\end{tabular}

$\mathrm{N}=$ Number of Patients, $\mathrm{SD}=$ Standard Deviation, $\mathrm{IR}=$ Interquartile Range, $\mathrm{P}=$ Significance.

DHT $=$ Dihydrotestosterone, DHEAS $=$ Dihydroepiandrosterone Sulphate. 
Table-II: Correlation between Levels of Hormones \& Severity (Spearman Correlation).

\begin{tabular}{llcc}
\hline Correlation & $N$ & $r$ & $P$ \\
\hline Testosterone VS Severity & 270 & 0.077 & 0.205 \\
DHT VS Severity & 270 & 0.085 & 0.165 \\
DHEAS VS Severity & 270 & 0.104 & 0.088 \\
\hline **. Correlation is significant at 0.01 level (2 tailed) \\
N= Number of Patients, \\
SD= Standard Deviation, \\
P = Significance, \\
DHT = Dihydrotestosterone, \\
DHEAS = Dihydroepiandrosterone Sulphate, \\
P = Significance, r = Correlation Co-efficient.
\end{tabular}

(Table-III). Although there is a statistically significant difference in the values of hormones, there is no proportional correlation with severity (Table-II).

\section{DISCUSSION}

In this study, the median age was 20 years. In the study by Kiyani et al., ${ }^{10}$ the mean age was $21.48 \pm 4.73$ years. In the study by Rahaman et al in India, ${ }^{11}$ the mean age of patients was 19.83 years, similar to this study. In the study by Saleh et al. ${ }^{12}$ the mean age was $21.17 \pm 4.21$ years, also similar to this study. This coincides with the sebaceous activity at this age group under influence of androgens. ${ }^{4}$

Thirty six percent patients had mild, 40\% moderate and $24 \%$ had severe disease. The highest proportion comprised of patients with mild disease. This is similar to the study by Kaiyani et al. ${ }^{10}$ This can be attributed to the inclusion criteria of selecting cases presenting for the first time.

The levels of androgenic hormones are given in Table-I. In the study by Da Cunha et al., ${ }^{13} 54 \%$ of the patients had hyperandrogenism and DHEAS levels were most frequently elevated. In the study by Borgia et al., ${ }^{14}$ there was elevation of at least one androgen.

Marynick SP et al. ${ }^{15}$ in their study found that affected patients had increased testosterone and DHEA-S levels. In the study by Slayden $\mathrm{M}$ et al., ${ }^{16}$ acne was related to hyperandrogenism irrespective of the age of presentation. Sixty-three percent of patients had at least one androgen level above 95\% of normal. The levels of Total $\mathrm{T}$ were elevated in $38 \%$ of patients in 12-18 years of age and 5\% in the $19-43$ years age group, DHEAS levels were elevated $(>7.6 \mu \mathrm{mol} / \mathrm{L})$ in $75 \%$ cases in $12-18$ years and in $36 \%$ in $19-43$ year age group. In the study by Uysal et al. ${ }^{8}, 55 \%$ of women with acne had elevation of at least one androgen.

In this study, there was a significant difference in androgen levels between cases and controls (Table-I). In another study ${ }^{17}$ there was no difference between cases and controls in case of Total Testosterone, Free Testosterone and DHT except DHEAS (P value $<0.05$ ). In the study by Vexaiu et al., ${ }^{18}$ there was a significant difference in levels of androgenic hormones between cases and controls, namely Testosterone $0.5 \mathrm{ng} / \mathrm{ml}$ versus $0.35 \mathrm{ng} /$ $\mathrm{ml}$, Andostenedione $2.2 \mathrm{ng} / \mathrm{dl}$ versus $1.3 \mathrm{ng} / \mathrm{dl}$, DHEAS $3.5 \mu \mathrm{g} / \mathrm{dl}$ versus $2.5 \mu \mathrm{g} / \mathrm{dl}$ in cases and controls respectively. In the study in Bangladesh, ${ }^{19}$ $10 \%$ acne patients had testosterone above normal levels.

There was no significant correlation of androgens with severity (Table-II) with Spearman Correlation. In the study by Kaiyani et al., ${ }^{10}$ no statistically significant relationship was demonstrated between testosterone levels and acne severity. In the study in Iran by Zandi $S$ et al., ${ }^{20}$ comparison of hormones

Table-III: Comparison of Level of Androgenic Hormones between different grades of Severity.

Since the data is non-parametric, median values are considered and mean/SD are obliterated.

\begin{tabular}{|c|c|c|c|c|c|c|}
\hline & Severity & $N$ & Median & $I R$ & $x^{2}$ & $P$ \\
\hline \multirow[t]{3}{*}{ Testosterone $(\mathrm{ng} / \mathrm{ml})$} & Mild & 97 & 0.65 & $(0.51,5.2)$ & 14.04 & 0.001 \\
\hline & Moderate & 108 & 1.4 & $(245.57,370.27)$ & & \\
\hline & Severe & 65 & 2.48 & $(238.75,413.50)$ & & \\
\hline \multirow[t]{3}{*}{ DHT (pg/ml) } & Mild & 97 & 404.97 & $(271.45,493.80)$ & 2.99 & 0.223 \\
\hline & Moderate & 108 & 367 & $(283,600.50)$ & & \\
\hline & Severe & 65 & 359 & $(289,534.6)$ & & \\
\hline \multirow[t]{3}{*}{ DHEAS $(\mu \mathrm{g} / \mathrm{ml})$} & Mild & 97 & 1.7 & $(1.20,2.40)$ & 6.37 & 0.041 \\
\hline & Moderate & 108 & 1.98 & $(1.39,2.69)$ & & \\
\hline & Severe & 65 & 1.8 & $(1.40,2.43)$ & & \\
\hline
\end{tabular}

$\mathrm{N}=$ Number of Patients, $\mathrm{SD}=$ Standard Deviation, $\mathrm{IR}=$ Interquartile Range, $\mathrm{P}=$ Significance.

$\mathrm{DHT}=$ Dihydrotestosterone, DHEAS $=$ Dihydroepiandrosterone Sulphate, $\mathrm{P}=$ Significance . 
between patients having PCOS and non-PCOs, levels of testosterone and dihydroepiandrosterone were not statistically significant. In the study by Aizawa et al., ${ }^{17}$ there was no correlation between androgen levels and severity.

Adityan B et al. ${ }^{21}$ in their study found that there was no association between acne severity and hyperandrogenism. In the study by Borgia et al., ${ }^{14}$ although hyperandrogenemia was present, no correlation was found with severity. In the study by Henze et al., ${ }^{22}$ more than 30\% of patients had elevated testosterone or DHEAS levels. However, large numbers with severe acne had normal androgens. This could be attributed to the fact that neither testosterone, nor DHEAS have strong androgenic potential in the pilosebaceous unit. Rather local enzymes are responsible for reduction of testosterone to 5a-dihydrotestosterone. Severe virilization could be caused by the overactivity of either 5- $a$ reductase ${ }^{22}$ or androgen receptor.

In this study, comparison of androgens between the three grades of acne revealed significant difference in Testosterone and DHEAS levels (Table-III), but not in DHT. In the study by Cibula et al., ${ }^{6}$ no positive correlation was found between acne severity and clinical/ laboratory values of androgenism. Women with increased severity had lower free testosterone. Contrary to this, in the study by Saleh et al., ${ }^{12}$ levels of testosterone, dihydroepiandrosterone and androstenedione were significantly raised in severe acne as compared to moderate $(\mathrm{p}=<0.005)$ and mild acne $(\mathrm{p}=0.001)$.

Lucky AW et al. ${ }^{23}$ in their study found that females with severe comedonal acne had significantly higher DHEA-S and testosterone levels. In the study by Seraifi et al., ${ }^{24}$ only DHEA-S was raised in women with acne but not hyperandrogenism, similar to this study. Similarly, in India ${ }^{25}$ although higher testosterone levels were found in cases compared to controls, statistically significant difference was observed in moderate and severe acne only. Thus, the role of androgens in acne pathogenesis can be observed by the difference in their serum levels, especially in the case of Testosterone and DHEAS. $^{25}$

\section{CONCLUSION}

Although androgenic hormones may be raised in the acne patients as compared to controls, only Testosterone and DHEA-S levels serve as markers of acne severity. Any therapy targeted towards acne and its severity can, therefore, be directed towards the ovarian androgen production, or blocking of androgen receptors in the pilosebaceous unit. Thus hormonal therapy can be an adjuvant to early treatment in acne.

Grant Support and Financial Disclosure: This study was carried out with the help of research grant from King Edward Medical University (Research Grant No. 22/2015-16/RGC/KEMU) as part of thesis for $\mathrm{PhD}$.

Conflict of interest: The authors declare no potential conflict of interest

\section{REFERENCES}

1. Balaji A, Rashmi K, Devinder M. Scoring systems in acne vulgaris. Indian J Dermatol Venereol Leprol. 2009;75(3):323. doi: 10.4103/0378-6323.51258

2. Tan J, Bhate K. A global perspective on the epidemiology of acne. Brit J Dermatol. 2015;172:3-12. doi: $10.1111 /$ bjd. 13462

3. Zouboulis CC, Katsambas AD, Kligman AM. Pathogenesis and treatment of acne and rosacea: Heidelerg: Springer; 2014. doi: 10.1007/978-3-540-69375-8

4. Zouboulis CC. Acne and sebaceous gland function. Clin Dermatol. 2004;22(5):360-366. doi: 10.1016/j. clindermatol.2004.03.004

5. Zouboulis CC, Degitz K. Androgen action on human skinfrom basic research to clinical significance. Exp Dermatol. 2004; 13:5-10. doi: 10.1111/j.1600-0625.2004.00255.x

6. Cibula D, Hill M, Vohradnikova O, Kuzel D, Fanta M, Zivny J. The role of androgens in determining acne severity in adult women. Br J Dermatol. 2000;143(2):399-404. doi: 10.1046/j.1365-2133.2000.03669.x

7. Aizawa H, Niimura M. Elevated serum insulin-like growth factor-1 (IGF-1) levels in women with postadolescent acne. J Dermatol. 1995;22(4):249-252. doi: 10.1111/j.13468138.1995.tb03381.x

8. Uysal G, Sahin Y, Unluhizarci K, Ferahbas A, Uludag SZ, Aygen $\mathrm{E}$, et al. Is acne a sign of androgen excess disorder or not? Euro J Obstet Gynecol Reproduc Biol. 2017;211:21-25. doi: 10.1016/j.ejogrb.2017.01.054

9. Barros B, Thiboutot D. Hormonal therapies for acne. Clin Dermatol. 2017;35(2):168-172. doi: 10.1016/j. clindermatol.2016.10.009

10. Kiayani AJ. Association of Serum Testosterone and Sex Hormone Binding Globulin Levels in Females with Acne Based on its Severity. J Ayub Med Coll Abbottabad. 2016;28(2):357-359.

11. Rahaman SMA, De D, Handa S, Pal A, Sachdeva N, Ghosh $\mathrm{T}$, et al. Association of insulin-like growth factor (IGF)-1 gene polymorphisms with plasma levels of IGF-1 and acne severity. J Am Acad Dermatol. 2016;75(4):768-773. doi: 10.1016/j.jaad.2016.05.019

12. Saleh BO. Role of growth hormone and insulinlike growth factor-I in hyperandrogenism and the severity of acne vulgaris in young males. Saudi Med J. 2012;33(11):1196-1200.

13. Da Cunha MG, Fonseca FLA, Machado CDAS. Androgenic hormone profile of adult women with acne. Dermatology. 2013;226(2):167-171. doi: 10.1159/000347196 
14. Borgia F, Cannavo S, Guarneri F, Cannavo SP, Vaccaro M, Guarneri B. Correlation between endocrinological parameters and acne severity in adult women. Acta Dermatovenereologica-Stockholm. 2004;84(3):201-204. doi: 10.1080/00015550410023248

15. Marynick SP, Chakmakjian ZH, McCaffree DL, Herndon $\mathrm{Jr} \mathrm{JH}$. Androgen excess in cystic acne. New Eng J Med. 1983;308(17):981-986. DOI: 10.1056/NEJM198304283081701

16. Slayden SM, Moran C, Sams Jr WM, Boots LR, Azziz R. Hyperandrogenemia in patients presenting with acne. Fertil Steril. 2001;75(5):889-892.

17. Aizawa $H$, Nakada $Y$, Niimura M. Androgen status in adolescent women with acne vulgaris. J Dermatol. 1995;22(7):530-532. doi: 10.1111/j.1346-8138.1995.tb03440.x

18. Vexiau P, Husson C, Chivot M, Brerault J-L, Fiet J, Julien R, et al. Androgen excess in women with acne alone compared with women with acne and/or hirsutism. J Invest Dermatol. 1990;94(3):279-283.

19. Rahman MM, Sikder MAU, Rashid MM, Khondker L, Hazra SC, Nessa M. Association of serum testosterone with acne vulgaris in women. Bangabandhu Sheikh Mujib Med Uni J. 2012;5(1):1-5.

20. Zandi S, Farajzadeh S, Safari H. Prevalence of polycystic ovary syndrome in women with acne: Hormone profiles and clinical findings. J Pak Assoc Dermatol. 2016;20(4):194-198.
21. Adityan B, Thappa DM. Profile of acne vulgaris-A hospitalbased study from South India. J Dermatol Venereol Leprol. 2009;75(3):272. doi: 10.4103/0378-6323.5124

22. Henze C, Hinney B, Wuttke W. Incidence of increased androgen levels in patients suffering from acne. Dermatology. 1998;196(1):53-54. doi: 10.1159/000017867

23. Lucky AW, Biro FM, Simbartl LA, Morrison JA, Sorg NW. Predictors of severity of acne vulgaris in young adolescent girls: results of a five-year longitudinal study. J Pediat. 1997;130(1):30-39. doi: 10.1016/S0022-3476(97)70307-X

24. Seirafi H, Farnaghi F, Vasheghani-Farahani A, Alirezaie NS, Esfahanian F, Firooz A, et al. Assessment of androgens in women with adult-onset acne. Int J Dermatol. 2007;46(11):1188-1191. doi: 10.1111/j.1365-4632.2007.03411.x

25. Krishna KH, Aruna G. Demographic and hormonal profile of acne in adolescence and post adolescence. Int J Sci Res. 2018;7(2).

\section{Authors' Contribution:}

UI: Conceived, designed, and performed statistical analysis.

NC: Helped in analysis and interpretation of data, final approval of the manuscript. 